\title{
Utility of Interactive Teaching Tools in Classroom Teaching: A Review of literature
}

\author{
Dhananjay Shrikant Kotasthane* and Vaishali Dhananjay Kotasthane,
}

Department of Pathology, Mahatma Gandhi Medical College and Research Institute, Pillayarkuppam, Puducherry, India

\section{ABSTRACT}

Change in medical education is needed to prepare doctors to meet the challenges of changing trends in the health care delivery system.Most of the medical schools have traditional, teacher-centered training.Most of the current undergraduate training is didactic and pedagogical, with the teacher as a source of information, which encourages students for surface learning. The most popular and widespread teaching method is lecturing.In a lecture, learners are passive.It haslowestretention value of all teaching techniques.

After reviewing literature, it was noted from various studies that incorporation of various interactive techniques, viz,brainstorming,think pair and share,Multiple choice questions,role play, word puzzles, quiz, group tasks,Problem based learning,case based learning help to achieve learning objectives in a student centric manner..Also, from review of literature it is found that interactivity makes the students more attentive and enthusiastic. Incorporation of interactivity in lectures has been found to improve teaching-learning process by educators who utilized interactivity in classroom teaching.

Interactive teaching in medical education is need of hour to be introduce to achieve goals of learning outcomes of undergraduate teaching

Keywords: Medical Education, Medical Education Technology, Interactive Teaching Tools.

\section{Introduction}

Change in medical education is currently a worldwide phenomenon. It is needed to prepare doctors to fulfill the expectations of society, to cope with the exponential growth of medical and scientific knowledge, to inculcate physicians' ability for lifelong learning, to ensure mastery in information technology and to adjust medical education to changing trends in the health care delivery system. These trends have been introduced in the different health institutes in most of the developed countries. ${ }^{(1)}$ In India, greater efforts are to be taken to orient teachers about these trends to bring desired changes in medical education to produce need-based human resources for health in the region. However, such a shift from traditional approach to a need-based approach requires a fundamental change of the roles and commitments of educators. ${ }^{(1)}$ Most of the medical schools have traditional, teacher-centered and hospital-based training with a few exceptions only. ${ }^{(1,2,3,4)}$

The broad goal of this study was to assess the effect of utilizationof interactive tools in lectures.

Self-directed learning involves the learner as an active participant and encourages the development of deep learning. Most of the current undergraduate training is didactic and passive with teacher as a centre for learning and as a source of information. In contrast to this, Learnercentered learning is an active process, where the student learns through his own study ${ }^{(5)}$ Moreover, the approach motivates students to adapt to the new knowledge, challenges, and problems he willencounter in future in his professional life. The key features of self-directed learning concord with the principles of adult learningand also with the findings of research in cognitive psychology ${ }^{(6,7,8)}$

Strategies that have been developed as self-directed learning include problem-based learning, interactive learning, discovery learning, task-based learning, experimental and reflective learning, portfolio-based learning; smallgroup, self instructional and project-based learning, peerevaluation and learning contracts. ${ }^{(6)}$

In traditional didactic teaching, the teacher is responsible for learning, teaching is an instructive process, learners are passive, the teacher is an instructor and a lecturer, the learner has only written, taped or broadcast material and the learner receives information. ${ }^{(9)}$

In contrast to this, in collaborative learning,the learner is responsible for learning,teaching/learning is a constructive process, learners are active,the teacher is a facilitator and a counsellor (the teacher acts as a tutor), the learner has a possibility to reach a wide range of information via new educational technology and the learner is a creative person who solves problems and uses informationcollaborative work. ${ }^{(9)}$

Consequently, the typical teaching methods and resources/ activities which take place in the two scenarios also differ. ${ }^{(9)}$ 
In traditional didactic teaching process - resources/ activities include Lectures, Seminars, and Films, audio and video tapes, printed material, Radio broadcasts and TV broadcasts. While incollaborative learning - resources/ activities include Project learning and problem solving, formulating a question/thesis/problem, answering a question or solving a problem,preparing a report/proposal/ plan, designing a prototype/ conducting a project. ${ }^{(9)}$

Wagner defined interactivity as "reciprocal events that require at least two objects and two actions.Interactions occur when these objects and events mutually influence one another". ${ }^{(10)}$ Interactive teaching is a two-way process of active participant engagement with each other, the facilitator, and the content. ${ }^{(9)}$ When compared to traditional learning, collaborative learning promotes more critical thinking skills such as analysing, evaluating, synthesising and applying information. It also promotes more social skills and a self directive way of learning. Self-direction means that the learner has to take more responsibility of his/her own learning. Collaborative learning methods are becoming more and more common and popular, but are often difficult, time consuming or expensive to put into practice. ${ }^{(9)}$ In Studies that focus on the interactivityand its derivatives, Daniel and Marquis ${ }^{(11)}$, Moore ${ }^{(12)}$, Wagner ${ }^{(13)}$, Markwood and Johnstone ${ }^{(14)}$, Barnard ${ }^{(15)}$, Parker ${ }^{(16)}$ and Blurtoon $^{(17)}$ have found interactive teaching tools to be far superior to traditional didactic methods. Moore offers three types of interactivity. ${ }^{(12,18,19)}$ In Moore's typology we have learner-content, learner-instructor, and learner-learner interactivity. Learner-content interactivity is illustrated by a student reading a book or a printed study guide. Instructorlearner interaction is the core of the teaching process. The success of the course design will depend largely on whether the conversation between teacher and learner is such that the learner can increase self-direction and construct new knowledge or not. Learner-learner interaction involves students working together to discuss, debate and attempt to solve problems that arise in their study of the course materials. ${ }^{(17)}$. Markwood and Johnstone provide fourth type of interactivity. The fourth type of interaction is one of interaction through electronic exchange, with students electronically or digitally sharing the results of newly formed knowledge over a period of time ${ }^{(14)}$ Anderson and Garrison described the three common types of interaction viz, student-student; student-teacher; student-content as illustrated in Figure 1. ${ }^{(20)}$

Interactive teaching values student's prior ideas and aims at empowering students to be independent learners. For teachers it offers an opportunity to learn along with the students and to use their interactive skills to listen carefully and challenge misconceptions where possible. To find the time to diagnose what students understand, either individually or as a group, and then to challenge them to enrich their thinking, requires a class management style that allows teachers space to interact. ${ }^{(9)}$

Mathew L Costa et al have found in their study that interactive teaching methods are superior to conventional didactic teaching, ${ }^{(21)}$ There was a consistent suggestion in the literature that shifting the balance of interaction in classrooms towards the dialogic end of the scale would bring improvements to the learning process and consequently to attainment outcomes. ${ }^{(22)}$

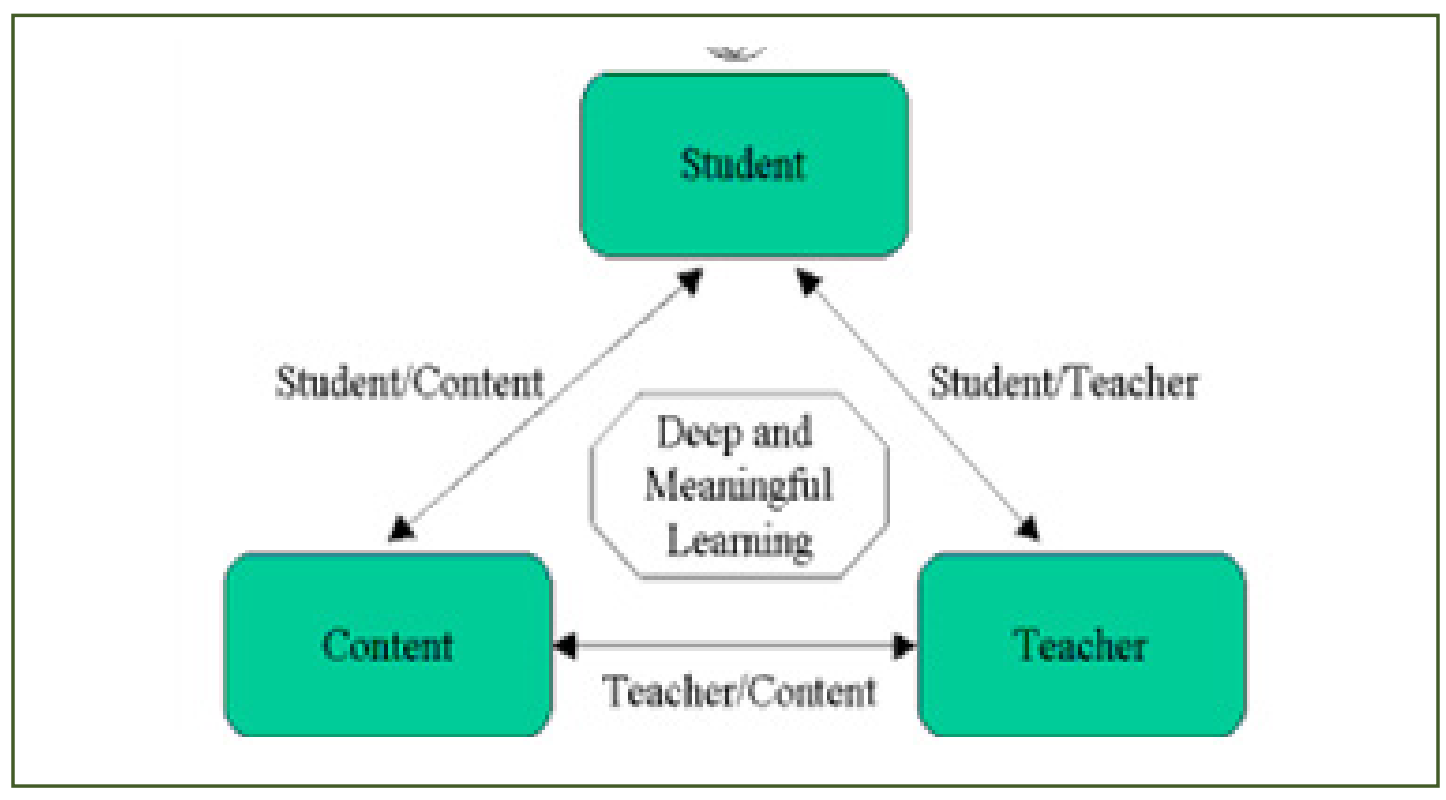

Fig. 1: Types of interaction as described by Anderson and Garrison. 
Interactive teaching methodology is becoming one of the important teaching modalities as against didantic lectures, thanks to recent brainstorming in the field of medical education technology(MET) in developing countries like India. Developed countries are way ahead in this MET and have already successfully implemented their student centric, skilled based curriculum. Accordingly, many medical institutes/universities in India where medical education unit is highly functional, have already started to implement innovations in medical curriculum. In this, interactive teaching is becoming a stepping stone/step forward in student-centric learning process. After reviewing articles from different corners of India for interactive teaching, it was interesting to see that wherever it was introduced ,students' feedback was very positive and demanded for continuation of this format. Study from D Y Patil deemed university showed perspectives of II MBBS students in Pathology regarding interactive teaching methods such as group discussions, brainstorming session, question answer sessions, multiple choice questions(MCQs), confusion technique and summaries. ${ }^{(23)}$ Their study showed good internal consistency with Crohnbach SQ alpha coefficient of 0.9 . They found most popular interactive mode to be MCQs(76\%) followed by brainstorming (64\%) and confusion technique(53\%).End result of this learning outcomes student noted were improved communication skills, retention of topic, improved attention span.Another study from Northern India(Haryana) introduced interactive teaching in the form of case based scenario,think pair and share,quiz and role play. ${ }^{(24)}$ The feedback from students showed encouraging results regarding their perceptions of interactivities with $75.2 \%$ of the students strongly agreed that sessions were enjoyable than traditional didactic lectures. Also, it stimulated thinking(78\%) regarding the topic. They were also more enthusiastic, motivated to take part in discussion. Similarly, one more study from Amritsar also took feedback in the form of questionnaire on interactive teaching techniques such as small group activity, brainstorming ,think pair and share sessions, demonstrations with the help of audio-visuals, role play, problem-solving, directed listening, case-based examples ,pre and post testing. ${ }^{(25)}$ The result of questionnaire showed that $85 \%$ students favored computer aided teaching as most reliable technique, $90 \%$ found audiovisual aids develops the ability to understand the topic better, $70 \%$ responded that Group teaching to be good learning experience, $90 \%$ found Role plays and simulation more interactive.

Thus, from the findings of our study and the literature reviewed, incorporation of interactivity in classroom teaching definitely improves teaching- learning process. It promotes self directed learning, prolongs retention of the subject in one's memory and creates more interest in the subject. Shift from the traditional teacher centered, pedagogic teaching approach to new student centered adult learning approach is the need of the present hour. Introduction of innovative tools like interactivity in class room teaching can help to achieve this goal.

In the present study, we have focused on interactivity in lectures as a method of collaborative learning. Possibly the most popular and widespread teaching method is lecturing, in which the teacher gives information and the students listen or take notes. Lecturing is a useful way of imparting a great deal of information quickly, but it is passive for students. Keeping the students' attention is a major dilemma educators have to face. The best use of lecturing is in combination with other methods; this helps students retain their interest and attention, allows for more student participation, and emphasizes different learning styles. Lecturing delivers "concepts", delivers a lot of information in a short amount of time andconveys information that is difficult to present in another way. Overuse of lecturing should be avoided because in a lecture your learners are passive, doesn't guarantee understanding, no feedback from learners, easily bores the audience unless well prepared and has lowest retention value of all teaching techniques. People generally listen for only 15-20 minutes without a break, people learn more when given an opportunity to process what they are learning. People retain more if they review or use the information immediately after learning it.

Interactive Teaching involves facilitator and learners, encourage and expect learners to participate, use questions to stimulate discussion, emphasizing the value of answers, give participants hands-on experience, use teaching aids to gain and retain attention.Participants like to be actively involved .Participants want to share knowledge and ideas. Teacher doesn't have to be an expert and answer all questions, because learners can address questions as well.

Judicious incorporation of interactivity in lectures leads to learner -content, learner-learner and learner-student interaction, which makes teaching learning process easier, interesting and fruitful.

\section{References}

1. Majumder A, D'Souza U, Rahman S. Trends in medical education: Challenges and directions for need-based reforms of medical training in South-East Asia. Indian J Med Sci 2004;58:369-80

2. Majumder MA. Today's students tomorrow's physician: Emerging challenges for undergraduate medical education. Bangladesh med J 2003;32:84-7.

3. Majumder MA. Medical Education in Bangladesh: Past Successes, Future Challenges. Bangladesh Med J 2003; 32:37-9. 
4. Majumder MA. Issues and priorities of Medical Education Research in Asia. Ann Acad Med Singapore 2004;33:257-63

5. Barrows HS, Tamblyn R. Problem-based Learning: An Approach to Medical Education. New York: Springer, 1980.

6. Spencer JA, Jordan RK. Learner-centered approach in medical education. BMJ 1999; 318:1280-3.

7. Knowles M. The adult learner: a neglected species.4th ed. Houston, TX: Gulf Publishing, 1990.

8. Regehr G. Norman GR. Issues in cognitive psychology: implications for professional education. Acad Med 1996; 71:988-1001.

9. Michael Hegarty, Anne Phelan, Lisa Kilbride.Blueprint for Interactive Classrooms.In Classrooms for Distance Teaching and Learning - A Blueprint.Belgium:Leuven University Press,1998. (Site updated: 30 April 2002) available from:http://bic.avnet.kuleuven.be/products/ handbook/handbookchapters/08chapter2.html

10. Wagner, J. Learning from a distance, The International Journal of Multimedia, 1994;19 (2): 12-20.

11. Daniel, J., C. Marquis. Independence and interaction: Getting the mix right, Teaching at a Distance, 1993;15:445-460.

12. Moore, M. Editorial: distance education theory, The American Journal of Distance Education.1991; 5(3): 1-6.

13. Wagner, E.D In support of a functional definition of interaction. American Journal of Distance Education,1994; 8(2): $6-26$.

14. Mark wood, R. S. John stone. New Pathways to a degree: Technology opens the college, Western Cooperative for Educational Telecommunications, Western Interstate Commission for Higher Education, Boulder, CO.1994

15. Barnard, R. Interactive Learning: A Key to successful distance delivery, The American Journal of Multimedia, 1995; 12: $45-47$.
16. Parker, Angie. Interaction in Distance Education: The critical conversation, Education Technology Review.1999; 13.

17. Bluurton, C. New Directions of ICT -use in education, UNESCO's World Communication and Information Report 1999.

18. Moore, M. Three types of interaction, The American Journal of Distance Education, 1992;3 (2):1-6.

19. Moore, M. Theory of transactional distance Education.In Desmond Keegan (Ed) Theoretical Principles of Distance Education, London \& New York: Routledge. 1993 p:22-38

20. Anderson, T., and Garrison, D. R. Learning in a networked world: New roles and responsibilities. In C. Gibson (Ed.), Distance Learners in Higher Education. Madison, WI: Atwood Publishing.1998.p.97-112

21. Matthew L Costa, Lee Van Rensburg, Neil Rushton.Does teaching style matter? A randomised trial of group discussion versus lectures in orthopaedic undergraduate teaching. Medical Education2007;41(2):214-217

22. Gary Beauchamp,Steve Kennewell. Interactivity in classroom and itsimpact on learning.Computers and education 2010:54(3): 759-766.

23. B u c h A C , C h a nd a n w a le S S, B a m n i kar S A. Interactiveteaching:Understanding perspectives of II MBBS students in Pathology.Med. J DY PatilUniv2014;7:693-695

24. Gupta A, BhattiK, WaliaR,AgnihotriP,KaushalS. Implementation of Interactive Teaching Learning Methods in Large Group in Endocrine Pharmacology.Ind J Pharmac and Pharmaco ,October-December 2015;2(4);197-202

25. Kaur D, Singh J, Seema,MahajanA,KaurG.Role of interactive teaching in Medical Education .Inter J Basic and App Med Scie,Sept- Dec 2011;1(1):54-60

*Corresponding author:

Dr Dhananjay Shrikant Kotasthane, Professor and HOD Department of Pathology, Mahatma Gandhi Medical College and Research Institute, Pillayarkuppam, Puducherry - 607402, India.

Email: dskotasthane@gmail.com

Date of Submission : 10.02.2017

Date of Acceptance : 24.02.2017

Financial or other Competing Interests: None.

Date of Publication : 28.02.2017 